\title{
Philosophical Medical Ethics
}

\section{Conclusion: the Arthur case revisited}

\author{
RAANAN GILLON
}

I started this series with two moral arguments that stemmed from a well known legal case. One argument rejected as wrong Dr Arthur's prescribing of dihydrocodeine and "nursing care only" for a rejected newborn infant with Down's syndrome and the other defended what he did as right. Seeking to show the complexity of reasoning that should underlie the conclusions "he was right" or "he was wrong," I extracted many moral claims and assumptions made in each argument. In the subsequent 24 articles I analysed many of these. What, if any light can such analyses shed on those opposing arguments about the Arthur case? The first point is that these issues are exceedingly complex. Next it should be clear that rational arguments for each side of this case can be mounted by sincere people anxious to come to right conclusions. Thus it is inappropriate to assume stupidity, ignorance, or ill intent in those who reach opposing conclusions to one's own in medicomoral arguments.

\section{An approach to moral dilemmas}

In medicomoral dilemmas I have suggested looking at the relevance of the four principles outlined by Beauchamp and Childress $^{1}$ and acceptable within a variety of moral theories. (Of course other methods could be and have been devised. $\left.{ }^{2}\right)$ These principles are respect for autonomy, beneficence, non-maleficence, and justice. I have also indicated that the moral analysis may sometimes turn on issues of scope-what moral duties do we have to this particular entity or type of entity? Whatever moral duties we may have to experimental rats, for example, we do not have to respect their autonomy, because rats cannot have autonomy and so cannot fall within the scope of respect for autonomy. In the Arthur case it seems to me that the crucial first moral question is indeed a question of scope: Do the same moral obligations that we have to our other patients extend to newborn infants with Down's syndrome? If the answer is yes our moral analysis will travel down the same path as in any moral dilemma concerning our patients-we will have the same sort of moral obligations to that newborn baby as we have to any other temporarily or permanently non-autonomous patient. If, on the other hand, the answer is no we do not have the same moral obligations to that baby as we have to our patients in generalsuppose, for example, we have obligations more stringent than we have to a fetus but less stringent than we have to a young child - then our analysis will follow a different path, more like that followed when we consider our moral obligations to fetuses.

\section{Imperial College of Science and Technology, London SW7 1NA}

RAANAN GILLON, MB, MRCP, director, Imperial College health service, editor, Fournal of Medical Ethics, and associate director, Institute of Medical Ethics

\section{Moral decisions imposed by the nature of things}

It seems that the scope of our moral obligations may be determined in several ways. Sometimes it is determined by individual and morally optional decisions; thus we can create self imposed moral obligations to some people and not others-for example, I may take on a previously non-existent moral obligation by promising one or more people that I will do something. Sometimes the scope of a moral obligation is determined by the morally optional decisions of a group of people. Such are the special moral obligations taken on by doctors, nurses, and lifeboatmen (and possibly clergy?). Sometimes the scope of a moral obligation is determined by the laws or customs of a particular society. One society may require its members to help the sick and poor, another may leave this to individual charity. One society may require children to look after their aging or sick parents, another may regard this as morally optional. I assume that the special moral obligations that we owe our family, neighbours, community, tribe, group, and nation are of this variable and socially determined kind.

Sometimes, however, the scope of our moral obligations seems not to be optional. Instead these obligations derive from the nature or certain sorts of entity. I take it that there is something about the nature of other people (including our patients) that we recognise to impose on us certain sorts of moral obligations, to require from us a certain sort of moral respect. We recognise, moreover, that we have no moral option about acknowledging these obligations. I take it that there is something different about the nature of waxworks, statues, or even dead bodies that allows us not to have the same moral obligations to them that we would acknowledge to the people they resemble (and, in the case of the bodies, were). Similarly, there is a morally relevant difference between pheasants and peasants which allows us to shoot one but not the other. Conversely, if there is no such difference then we are morally obliged to eschew such discrimination and be ready to shoot both or neither.

\section{Which properties of things are morally relevant?}

Such questions are crucial to discussion of a wide variety of medicomoral issues, including contraception, postcoital contraception, research on embryos, abortion, severe brain damage, persistent vegetative state, brain stem death, and traditional cardiorespiratory death. Characteristics of things that have been plausibly argued to be criteria for moral categorisation include membership of particular species, notably the human species, possession of the capacity to experience pain (sentience), and possession of the capacities of being a person, whatever those might be, but perhaps including the capacity of self awareness as a necessary condition. "Viability," arbitrary dates of gestation, and passage through the birth canal and its associated physiological changes are, like quickening, implausible criteria on which to base fundamental moral distinctions.

These are complex and contentious issues. Perhaps seeking to avoid becoming embroiled in them, doctors sometimes think that 
unless they confront a particular medicomoral problem in their practice-for example, abortion-they do not need to bother too much about the moral arguments concerning it. But is it not obvious that any doctor who ever accepts the moral legitimacy of abortion as a bona fide medical practice-and most do-really needs to work out why he can justify abortion but not killing his adult patients? In particular, ought he not to work out what morally relevant characteristics the abortable fetus lacks that are present in his adult patients, lack of which justifies the deliberate medical killing of the fetus when there is deep moral and legal opprobrium for the deliberate medical killing of adult patients? A very similar question applies to any doctor who supports what Dr Arthur did or, more generally, who believes that newly born severely handicapped infants may in some circumstances be killed or actively "allowed to die." What morally relevant characteristics are lacking in such infants that are present in adult patients? Alternatively, what morally relevant characteristics are present in such infants that require us to treat them differently from fetuses at various stages of their development?

\section{Handicapped neonates and handicapped adults}

One sort of answer to the first question is that there is no morally relevant difference between newborn infants with serious handicaps and adults with similar handicaps and that both groups should be treated similarly. What is morally permissible treatment for handicapped newborn infants is morally permissible for similarly handicapped adults and vice versa, and what is morally impermissible for handicapped adults is morally impermissible for similarly handicapped newborn infants, and vice versa. The first thing to note is that this leaves the abortion question unanswered: if the newly born handicapped infant ought to be treated in the same way as any other patient with an equivalent handicap, how has it changed since it was an abortable handicapped fetus? Secondly, this position rules out medical management of severely diseased or handicapped newborn infants that would be unjustifiable in similarly diseased or handicapped adults or older children. Thus a doctor who held this line and believed that the prescribing of dihydrocodeine and nursing care only would be wrong for an adult or older child with Down's syndrome would also have to reject Dr Arthur's action, as the "moral prosecution" argued. (To avoid this conclusion it might be argued that in fact Dr Arthur believed in those first few days that the infant had various probably fatal and untreatable cardiac and other abnormalities in addition to Down's syndrome, as the pathologist eventually showed. I know of no reason to make such an assumption, and no evidence was given at the trial to support it.)

\section{Standards of medical care}

To avoid the conclusion that management such as Dr Arthur's of an infant with uncomplicated Down's syndrome is morally wrong it might be argued that similar management would be justifiable with an older child or adult with uncomplicated Down's syndrome. How could such a line be sustained when it would allow a doctor, when faced with a patient with uncomplicated Down's syndrome whose parents do not wish it to live, to keep the patient in hospital; withhold any medical care he would normally be given; administer large doses of dihydrocodeine, knowing its depressive effects on respiration and appetite; and feed and hydrate the patient only on demand? Surely that would not be morally acceptable in an adult or older child with uncomplicated Down's syndrome? Why not? Because it would be widely agreed by doctors and society that having Down's syndrome does not in itself justify a reduction in the standards of medical care that patients in general are owed and which are not met by this hypothetical management of "nursing care only," large doses of dihydrocodeine, and feeding and hydration only on demand.

That is not to argue that if one believes that the newly born infant with Down's syndrome should be treated like any other patient then he or she has to be treated with the most effective available medical treatment in all circumstances. Ex hypothesi the same sort of moral assessment would apply to proposed treatments for the infant as for any other patient. What treatment would the patient choose if he could deliberate about it (proxy respect for autonomy)? How much net benefit over harm can reasonably be expected for the patient (beneficence and non-maleficence)? Here the precise nature of the medical condition, the degree of handicap, the expected effects on the patient of the management proposed, and the probability of achieving for the patient a substantial net benefit over harm are crucial moral issues and will all vary according to the circumstances. Finally, would the proposed treatment be just or fair to the patient and to others, both in the burdens it imposes on all concerned and in the benefits it offers to the patient and any other beneficiaries in comparison with the resources it removes from others (justice)? These, I have suggested, are standard moral questions that should apply to all medical care and use of medical resources, but the important thing is that they would apply no more and no less when considering the newly born infant with Down's syndrome than in any other allocation of lifesaving medical resources, if doctors owe the newly born infant with Down's syndrome the same moral obligations that they owe to all their patients.

\section{Down's syndrome and moral rights}

But perhaps they don't. One possible line of argument supporting a distinction between the moral obligations of doctors to patients with Down's syndrome and to patients in general might be that having Down's syndrome gives people fewer moral rights against doctors than they would otherwise have. Expressed in terms of doctors' duties, the claim would be that if a patient has Down's syndrome doctors have less stringent moral obligations towards him or her than they would normally have. But how could such a claim be justified? Without a rationale it is no more convincing than a similar claim about patients with Gilbert's syndrome or those who happen to have blue eyes. Perhaps the justification offered would be that Down's syndrome results in such a low quality of life compared with normal human flourishing that doctors are not morally obliged to treat patients with Down's syndrome? This is an argument that the right to life organisations and many others find particularly objectionable-rightly so.

Its implications are that people with Down's syndrome of any age and development, and any degree of handicap, are morally second class and can be "allowed to die" when those in the first class would be kept alive. Moreover, it implies that the same sort of moral discrimination is justified against anyone else with a similar quality of life to that of the least impaired person with Down's syndrome. Given the varying degrees of quality of life and the wide range of flourishing that older children and adults with Down's syndrome manifest, the argument that any person with Down's syndrome may be denied lifesaving medical care, let alone that such people may be actively "allowed to die," is clearly morally unacceptable. But why is it morally unacceptable? The answer is surely that there is something about the nature of older children and adults with Down's syndrome that makes us recognise a moral obligation to treat them as we treat each other. But what is different about them (a) compared with newborn infants with Down's syndrome, if we believe that we can treat the latter in lifethreatening ways that we find morally unacceptable in relation to other patients, including older patients with Down's syndrome; and $(b)$ compared with embryos and fetuses with Down's syndrome, if we believe that we may justifiably kill (abort) these?

\section{What is a person?}

One radical and contentious answer is that fetuses and newly born humans, whether they have Down's syndrome or not, are not people, whereas older children and adults, including those with Down's syndrome, are. According to this line of argument the "right to life" is a right of people or persons; the moral obligation not to kill others is a duty not to kill other people or persons. What is 
meant by "a person" and "people" in this context is inadequately worked out and a subject of vigorous philosophical debate. One line of argument is that a necessary condition for being a person, and thus for being owed the moral respect due to persons, including an intrinsic (though prima facie) moral right not to be intentionally killed by others, is awareness of oneself or self consciousness. (This line of argument stems from a discussion about the nature of persons by the physician-philosopher John Locke. ${ }^{+}$) It seems plausible that the morally special attributes that distinguish people from animals and other entities to which we do not accord an intrinsic right to life require a capacity for self consciousness. According to this argument self consciousness is not morally important in itself but is a necessary condition of all the remarkable and distinguishing characteristics that endow people with special moral importance and thus special moral rights. This argument supposes that all newborn infants, like all fetuses, are not self conscious and therefore cannot be people and therefore do not have an intrinsic moral right to life. Clearly part of the argument rests on empirical claims and requires appropriate empirical support, but there seems little doubt that newly fertilised ova are not self conscious and equally little doubt that adults are, therefore somewhere along the developmental line, perhaps gradually rather than suddenly, self consciousness must develop.

\section{The right to life and newborn infants}

Of course, even if this argument were accepted it does not imply that fetuses and babies should not in most cases be carefully protected. There are several justifications for such protection other than an intrinsic right to life. The first is that the development from newly fertilised ovum to self conscious human being is gradual, and there are plausible consequentialist reasons for reflecting such development by according gradually increasing moral protection to the developing embryo, fetus, and newly born infant. Secondly, in most cases mothers, fathers, families, and societies put enormous value on newly born babies-much greater value than, in our society, they typically put on the embryo and fetus-and thus there are important consequentialist reasons for reflecting this distinction in our social institutions. Thirdly, in most cases great personal and social anguish and disruption would result if newly born babies were not given very careful protection, especially by doctors.

None the less, if it is true that newly born infants have not yet developed into people and therefore do not yet have the full moral rights of people, including the "right to life," then it becomes justifiable for societies to determine that in certain circumstances the protection that should normally be extended to newly born infants may be withdrawn. In cases where an intrinsic right to life did not exist to function as a moral "trump card" such circumstances would be determined by considerations of overall harm and benefit, which took into account both the moral repugnance normally evinced at infanticide and also the harm to families and society of keeping alive unwanted severely handicapped infants. Given the great social disagreement over these issues it would, of course, be intolerable - even in merely consequentialist terms-to impose any such withdrawal of protection or "allowing to die." If the parents of severely handicapped newborn infants want them to be medically sustained then their wishes should if possible be respected-but if, having considered the matter, the parents want the infant to be painlessly "allowed to die" then according to this argument their wishes too can legitimately be respected.

\section{The question of acts and omissions}

Many doctors would support active "allowing to die" of the sort carried out by Dr Arthur but would reject any active killing of such infants. I believe I have shown that it is difficult to justify even active "allowing to die" unless it is also agreed that severely handicapped newborn infants are not owed the same moral duties, especially the duty to preserve their lives, that doctors owe to their patients in general. I have also argued previously, however, against the customary medical assumption that the distinction between acts and omissions can justify a moral distinction between withdrawal of medical treatment and active killing. A moral question has to be answered first-namely, which medical acts and omissions to act are morally justifiable and which are not? Knowingly causing conditions in which an infant is likely to die when it is otherwise unlikely to do so, and where there is no intention of benefiting the infant by doing so, is normally regarded as morally culpable, as murder or manslaughter. The father who killed baby Brown, also an infant with Down's syndrome, was jailed for manslaughter. What are the morally important differences between what he did and what $\mathrm{Dr}$ Arthur did? ${ }^{56}$ There is no reason to suppose that the verdict on baby Brown's father would have been ameliorated had his baby died because the father gave dihydrocodeine, fed and hydrated it only on demand, and then did not obtain medical care when it became ill. Such treatment could only be justified if $(a)$ the newborn infant, like the fetus, does not have an intrinsic right to life and $(b)$ there is sufficient justification in terms of overall benefit over harm (in this context restriction of such treatments to doctors and parents acting together may help to minimise the harm).

\section{A radical challenge}

Here, then, is a radical challenge to those who would support Dr Arthur's action. If they believe that they owe the same duty to respect the lives of newborn infants with Down's syndrome as they owe to all their other patients how do they justify their support of actions that they would almost certainly reject in older patients with Down's syndrome? (And if they also defend abortion-for example, of fetuses with Down's syndrome-how do they justify their different attitudes to the fetus and to the newborn infant?) If, on the other hand, they believe that they do not owe the same duty to newborn infants with Down's syndrome that they owe to their other patients, how do they justify this position without falling into the trap of denying all patients with Down's syndrome the moral protection they afford to their patients in general? I believe that the issue turns on the question of personhood and that it is because the newly born infant is not a person that it is justifiable in cases of severe handicap to "allow it to die" in the way Dr Arthur allowed baby Pearson to die. But while there may be some social benefits in distinguishing between actively "allowing to die" and painlessly killing such infants, there is, I believe, no other moral difference, and doctors who accept such "allowing to die" of severely handicapped newborn infants should not deceive themselves into believing that there is such a difference. Those who do not accept these radical claims yet wish to support action like Dr Arthur's need to cudgel their brains for a rationale, one that is consistent with their attitudes to abortion, the "morning after pill," embryo research, and the treatment of newborn infants with spina bifida or anencephaly, of patients with severe dementia, of patients in persistent vegetative state, and of those with "brain stem death." Such are the widespread ramifications of questions about the scope of our moral obligations to human beings at different stages of their lives.

\section{References}

1 Beauchamp TL, Childress JF. Principles of biomedical ethics. 2nd ed. New York, Oxford: Oxford University Press, 1983

2 Jonsen AR, Siegler M, Winslade WJ. Clinical ethics. London: Baillière Tindall, 1982

2 Jonsen AR, Siegler M, Winslade WJ. Clinical ethics. London: Baillière Tin
3 Brody H. Ethical decisions in medicine. 2nd ed. Boston: Little Brown, 1981

4 Locke J. Essay concerming human understanding. Book 2: chapter 27, section 9. London, 1690

5 Davis JA. The "baby Brown" case and the Dr Arthur verdict. I Med Ethics 1985;11:159.

6 Kennedy I. Response to professor Davis. F Med Ethics 1985;11:159-60. 